\title{
A IMPORTÂNCIA DO CONHECIMENTO EM MÚSICA NA FORMAÇÃO INICIAL DO PE- DAGOGO
}

Marcelo Luiz A. A. Carvalho, Patrícia L.L. Mertzig Gonçalves de Oliveira, Luciana Carolina Fernandes de Faria, Ana Carolina Brambati Teixeira, Kayná dos Santos Bezerra.

Universidade do Oeste Paulista - UNOESTE, Faculdade de Arte, Ciências, Letras e Educação, Presidente Prudente, SP. E-mail: $\underline{\text { mrllcarvalho@hotmail.com }}$

\section{RESUMO}

O presente artigo tem como objetivo discutir a importância do ensino da música na formação inicial do pedagogo. A hipótese adotada neste trabalho é que, na formação do pedagogo, a música é fundamental para o desenvolvimento dos indivíduos, possibilitando uma nova prática pedagógica no ambiente escolar. Para tanto, a pesquisa é de caráter bibliográfico e usa como fontes as Leis e outros Documentos Oficiais que estabelecem normas e diretrizes no intuito de verificar os limites e alcances que o conteúdo de música proporciona. Concluímos que apesar da falta de clareza dos conteúdos e metodologias em música apresentados nos Documentos Oficiais é importante que o pedagogo não encare esse conteúdo como entretenimento e sim busque em seu curso de formação inicial bases para uma prática sólida e criativa ao abordar a música em suas aulas.

Palavras-chave: Educação Musical. Pedagogia. Formação inicial de Professores.

\section{THE IMPORTANCE OF KNOWLEDGE IN MUSIC IN THE INITIAL FORMATION OF THE PEDAGOGUE}

\begin{abstract}
This article aims to discuss the importance of teaching music in the initial formation of the pedagogue. The hypothesis adopted in this work is that, in the education of the pedagogue, music is fundamental for the development of individuals, making possible a new pedagogical practice in the school environment. To do so, the research is bibliographic and uses as sources the Laws and other official documents that establish norms and guidelines in order to verify the limits and reaches that the music content provides. We conclude that despite the lack of clarity of content and methodologies in music presented in the Official Documents it is important that the pedagogue does not regard this content as entertainment, but rather seeks in his initial training course the basis for a solid and creative practice when approaching music in his Classrooms.
\end{abstract}

Keywords: Music Education, Pedagogy, Initial Teacher Training. 


\section{INTRODUÇÃO}

O presente artigo tem o olhar voltado para o ensino de música na formação inicial do pedagogo. Tendo como princípio a música como importante área do conhecimento para o pleno desenvolvimento humano e a Educação Musical também enquanto área de conhecimento que se concentra em desenvolver saberes relacionados ao ensino e a aprendizagem musicais, destacamos a importância desse conhecimento na formação do pedagogo para futura atuação em sala de aula.

Cientes de que a Educação Infantil e I Ciclo do Ensino Fundamental também contam com os professores especialistas nas áreas de conhecimentos Arte e Educação Física, partimos do princípio de que o pedagogo também pode envolver seus alunos em práticas musicais significativas e o quanto elas são importantes no processo formativo dos educandos.

A formação inicial, no atual contexto, é indispensável para a prática pedagógica em todas as áreas educacionais e não poderia ser diferente para o professor dos anos iniciais, visto que esse professor deve estar preparado para as mais diversas situações que envolvem os processos de ensino e de aprendizagem.

Atendendo ao que está determinado enquanto Lei maior, a Lei de Diretrizes e Bases da Educação Nacional (LDBEN 9394/96) que rege as políticas públicas educacionais as Diretrizes Curriculares de Formação Nacional dos Professores da Educação Básica (BRASIL, 2002), em que a formação do professor da educação básica se regulamenta, articula-se da seguinte forma:

Art. 10 As Diretrizes Curriculares Nacionais para a Formação de Professores da Educação Básica, em nível superior, em curso de licenciatura, de graduação plena, constituem-se de um conjunto de princípios, fundamentos e procedimentos a serem observados na organização institucional e curricular de cada estabelecimento de ensino e aplicam-se a todas as etapas e modalidades da educação básica (BRASIL, 2002, p. 1).

Ainda de acordo com as Diretrizes, a formação inicial do pedagogo deve ter como principal objetivo a docência. A diretriz deve ser vista como um processo pedagógico metódico e intencional, desenvolvendo-se na articulação entre conhecimentos científicos e culturais, compreendendo ainda a socialização e a construção do conhecimento entre os partícipes.

Segundo Freire (1996) é necessário que na prática da docência o sujeito não se comporte como único transmissor do conhecimento ou o único apto a ensinar, mas sim como sujeito que aprende e que cria possibilidades para uma nova construção do saber. É neste sentido que afirma Freire:

Ensinar não é transferir conhecimentos, nem formar é ação pela qual um sujeito criador dá forma, estilo ou alma a um corpo indeciso e acomodado. Não há docência sem discência, as duas se explicam e seus sujeitos apesar de diferenças que os conotam, não se reduzem à condição de objeto, um do outro. Quem ensina aprende ao ensinar e quem aprende ensina ao aprender (1996, p. 23).

Na prática docente o professor precisa ter coerência em relação ao conhecimento ensinado, pois é preciso saber vincular o conteúdo ao contexto social do aluno, colocando-se como aprendiz e fornecendo uma maior amplitude de aprendizagem, trazendo uma didática diferenciada que propicie a compreensão e a produção de novos conhecimentos. Nesta perspectiva, afirma Garcia (1999, p.86):

Conjuntamente com o conhecimento pedagógico, os professores têm de possuir conhecimentos sobre a matéria que ensinam. Quando o professor não possui conhecimentos adequados sobre a estrutura da disciplina que 
está a ensinar, o seu ensino pode apresentar erradamente o conteúdo aos alunos. O conhecimento que os professores possuem do conteúdo a ensinar também influencia o que e como ensinam.

Conjuntamente com o conhecimento pedagógico, os professores têm de possuir conhecimentos sobre a matéria que ensinam. Quando o professor não abrange conhecimentos adequados sobre a estrutura da disciplina que está a ensinar, a sua prática pode apresentar erradamente o conteúdo aos alunos. Não há como promover um desenvolvimento consciente de um determinado assunto se não se conhece este conteúdo.

No curso de pedagogia, o professor em formação deverá participar de situações de aprendizagem, que ampliem os horizontes da informação e do conhecimento, facilitem o acesso a manifestações culturais e que ele saiba conduzir as tecnologias, estando atento para as políticas públicas destinadas ao campo educacional; além de ter conhecimento das condições de trabalho e ser capaz de atuar na prática pedagógica de modo autônomo, frente aos conflitos, impasses próprios da profissão e compreender a formação contínua como meta após a conclusão do curso.

Nesse sentido os conteúdos e metodologias ligados a áreas artísticas tais como música, teatro, dança e artes visuais devem permear o currículo dos cursos de Pedagogia assim como os conteúdos e metodologias para o ensino de Ciências, Matemática, Língua Portuguesa, etc. Nas áreas artísticas verificamos que este conhecimento demanda tempo de estudo pois o domínio da linguagem musical, por exemplo, é tão complexo como de qualquer outra linguagem artística porém se faz necessário à formação do professor pedagogo.

O objetivo do presente artigo é refletir sobre a importância que o conhecimento em música proporciona ao pedagogo em sua formação inicial, ainda que a graduação em Pedagogia não se proponha a formar o professor especialista.

\section{METODOLOGIA}

A pesquisa será bibliográfica e documental e usará como fontes a Lei de Diretrizes e Bases da Educação Nacional, LDBEN 5692/71, a atual 9394/96 e a Lei 11.769/08 além de outros documentos oficiais como os Parâmetros Curriculares Nacionais (PCN) que estabelecem normas e diretrizes, norteando assim os limites e os alcances que o conhecimento em música proporciona para o pedagogo na formação inicial. O levantamento bibliográfico priorizará textos que abordem o tema de forma contextualizada com o recorte desejado que trata da formação inicial do pedagogo bem como a apresentação de Leis vigentes no Brasil que garantem a música como conteúdo obrigatório no espaço escolar. Os autores selecionados e seus pontos de vista encaminharam a discussão de forma a possibilitar ações futuras que auxiliaram a música e a educação musical a conquistar de forma eficaz e definitiva sua presença na escola quando também é abordada pelo pedagogo em sua prática docente.

\section{RESULTADOS}

A música, bem como outras modalidades artísticas, deve fazer parte dos conteúdos a serem desenvolvidos nos cursos de Pedagogia, visto que sua prática colabora para o desenvolvimento da experiência pessoal do sujeito. De acordo com a Lei de Diretrizes e Bases da Educação Nacional (LDBEN) no 9394 de 1996 as quatro linguagens artísticas são: Artes Visuais, Dança, Teatro e Música.

Nesse sentido, a música deve então ser desenvolvida nos anos iniciais, podendo ser incluída em propostas pedagógicas, integrando conhecimentos distintos e experiências de criação com o objetivo de garantir o direito dos/as estudantes ao exercício da autoria, do senso crítico e do trabalho coletivo, próprios dos processos de criação artísticos. 
É preciso garantir que o ensino da música tenha um lugar qualificado em todos os tempos e espaços escolares, estando presente nos currículos não como adorno, tampouco como atividade meramente festiva ou de entretenimento, mas como conhecimento organizado e sistematizado, que propicia aos estudantes a criação e a recriação dos saberes artísticos e culturais.

No início do século $X X$, observamos o surgimento dos métodos ativos desenvolvidos por educadores como Decroly, Montessori, Dalton, Pakhurst, entre outros. Para esses pensadores a música é tratada como um dos principais recursos didáticos para o sistema educacional, reconhecendo o ritmo como um elemento ativo da música, favorecendo, dessa forma, as atividades de expressão e criação. Quando falamos na natureza do conhecimento de música, estamos antes de tudo, pressupondo a existência de um conhecimento proveniente da experiência musical. A educação pela música torna possível abordagem poética na formação dos futuros professores.

A música é um elemento de fundamental importância, pois movimenta, mobiliza e por isso contribui para a transformação e o desenvolvimento. A música não substitui o restante da educação, ela tem como função atingir o ser humano em sua totalidade." (WILLEMS, apud GAINZA,1988, p.36).

As atividades musicais realizadas na escola não visam à formação de músicos, mas, contato, vivência e compreensão da linguagem musical. Por isso, propiciar a abertura de canais sensoriais, facilitando a expressão de emoções, ampliando a cultura geral e contribuindo para a formação integral do ser. A esse respeito Katsch e Merle-Fishman apud Bréscia (2003, p.60) afirmam que "(...) a música pode melhorar o desempenho e a concentração, além de ter um impacto positivo na aprendizagem de matemática, leitura e outras habilidades linguísticas nas crianças".

A atual LDBEN (BRASIL, 1996) estabelece "o ensino da arte" como "componente curricular obrigatório, nos diversos níveis da educação básica", garantindo um espaço para a(s) arte(s) na escola. No entanto, mais uma vez, esta determinação é apontada pela indefinição e ambigüidade, pois a expressão "ensino da arte" é marcada pela falta de precisão, podendo ter diferentes interpretações.

Algumas especificações a respeito são encontradas, por sua vez, nos Parâmetros Curriculares Nacionais (PCN) para os ensinos fundamental e médio (BRASIL, 1997, 1998, 1999), que configuram uma orientação oficial para a prática pedagógica e vêm sendo utilizados pelo MEC como referência para a avaliação das escolas e alocação de recursos. Em todos os documentos dos Parâmetros, a música integra a área de conhecimento Arte - ao lado de artes visuais (mais abrangentes que as artes plásticas), teatro, dança, e, especificamente no ensino médio, as artes audiovisuais.

No entanto, as decisões quanto ao tratamento das várias linguagens artísticas ficam a cargo de cada estabelecimento de ensino, aos quais cabe "elaborar e executar sua proposta pedagógica", de acordo com os princípios de flexibilidade e autonomia da LDB (Lei 9394/96, Art. 12). Por outro lado, nem a LDB, nem os PCN indicam com clareza qual deve ser a formação de quem ensina arte ou música nos diversos níveis da educação básica.

\section{DISCUSSÃO}

A Educação Musical no Brasil começou com a chegada dos Jesuítas, um pouco depois que o Brasil foi descoberto, e tinham como objetivo catequizar os índios por meio da música, pois os indígenas tinham uma forte ligação com tal manifestação artística por fazer parte dos seus rituais. Com a chegada da família real portuguesa em 1808, a música deixou de ser só um meio para ensinar, mas começou a ser utilizada em teatros e como forma de entretenimento, pois, com ela vieram muitos músicos e artistas. Por meio do Decreto $n^{\circ} 1.428$, de 12 de Setembro de 1854 no 
artigo $n^{\circ} 3$, era exigido na instituição de ensino um professor de canto e instrumento para uma melhor organização no ensino. E então, a música foi instituída na escola como ensino obrigatório, mas até então nada era dito sobre o professor ser especialista em música. Em 1931, o presidente da época, Getúlio Vargas assinou o Decreto 19.890 que institui o Canto Orfeônico na escola tornando-o disciplina obrigatória na escola.

Para complementar a demanda de professores para atuarem na área musical a Superintendência de Educação Musical e Artística (SEMA), fundada por Anísio Teixeira em 1932, disponibilizou cursos para os professores serem capacitados na área de música. Em 1971, a Lei 5692 juntava o ensino das artes no que era chamado de polivalência, em que um professor era responsável pelo ensino de Artes Visuais, Música, Dança e teatro. Com isso percebeu-se que os cursos de Licenciatura não eram suficientes para a formação desse professor, visto que a predominância nas aulas era do ensino de artes visuais, ou seja, professores foram despreparados para as salas de aula.

Com a LDB (Lei de Diretrizes e Bases da Educação) de 1996, n 9394, a música começa a fazer parte do currículo de artes, porém, somente como apreciação e para haja a interdisciplinaridade, não mais como ensino sistematizado e obrigatório na educação, ou seja, deixou de pensar na música como conteúdo importante para a formação humana para ser somente instrumento de ensino de outras matérias. Então em 2008, a mesma Lei é alterada e exige o ensino de música na educação básica e o torna obrigatório (Lei $n^{\circ} 11.769$ ), porém com todo o histórico da música na escola, nem mesmo a criação de uma lei não foi suficiente para mudar uma realidade, seria necessário promover ações para garantir o cumprimento da lei. Por exemplo, ao mudar o currículo dos cursos de pedagogia, a criança desde os primeiros anos tem contato com a música como matéria escolar, assim como português, matemática, história entre outras, fazendo com que ao decorrer dos próximos anos escolares isso faça parte do seu dia-a-dia.

Dessa forma, para que o ensino de música seja possível em sala de aula é necessário que o pedagogo conheça alguns conteúdos e metodologias em educação musical que acreditamos serem possíveis de serem trabalhados em suas aulas mesmo que sua formação não seja em música. Além disso destacamos aqui a importância do conhecimento musical não como entretenimento, mas sim como conhecimento sistematizado, proporcionando aos estudantes experiências musicais conscientes. Desse modo, no curso de pedagogia, é necessário que o educador que está cursando esteja qualificado a lidar com as diversas situações de aprendizagem, ao entendermos que ele é o mediador da cultura no âmbito escolar, o mesmo deve estar preparado para isso.

Ao abordarmos a música como foco deste artigo e a sua importância no currículo dos cursos de pedagogia, acreditamos que ela deve fazer parte dos conteúdos, pois contribui para o aperfeiçoamento da experiência pessoal do estudante de pedagogia. Compreendemos a dificuldade do pedagogo em ministrar diferentes disciplinas e áreas do conhecimento nos anos iniciais, porém a música e a arte também são parte da formação básica e não dever ser abordada como menos relevante. Ter a oportunidade de conhecer e desenvolver o conhecimento artístico é direito de todos, principalmente para os pedagogos que ensinam a base na educação infantil.

De acordo com Figueiredo (2004, p. 60) "Aproximar música e pedagogia pode representar uma alternativa para que a educação seja compreendida, solicitada e aplicada sistematicamente". Oferecer esse ensino aos pedagogos não substitui o cargo do professor de música, mas tendo essa especialização eles têm a chance de inserir com maior facilidade a música na escola. Porém, é de extrema importância que o ensino de música seja inserido aos pedagogos de maneira consciente, de maneira integral durante os anos de estudo para que se possa desenvolver atividades com maior compreensão para que assimilem os conteúdos musicais. O problema é que não há clareza nos conteúdos de música e é por isso que não são ensinados em sala de aula, quando forem esclarecidos, o educador incluirá na sua prática. 
Segundo Faria (2016, p 79) "Conhecer a música não é apenas saber tocar um instrumento, é conhecer e dominar a linguagem e ter sua percepção ativa, crítica, consciente e autônoma." Assim, compreendemos a função social da música, o papel da educação musical na escola como um conhecimento que proporcione aos estudantes uma forma de expressar os sentimentos de forma ampla em ambientes que desenvolvam a criatividade.

\section{CONCLUSÃO}

O ponto central desde artigo é refletir que o ensino da música é essencial para a formação humana. Existem muitas atividades que podem ser propostas em sala de aula como: apreciação musical, que é um conteúdo em que o objetivo é deixar a escuta do aluno mais consciente, brincadeiras e jogos musicais que proporcionam aos alunos a experiência e o conhecimento em música, possibilitando o mesmo a ter um senso mais crítico, a explorar o trabalho em equipe, e a criação artística, que é o ponto principal da educação musical na escola. E ao realizar essas atividades na escola, não estamos visando formar músicos, mas sim, em proporcionar aos alunos toda essa experiência, desenvolvendo a criatividade, expressão, coordenação, concentração, contribuindo para o desenvolvimento cerebral e para a formação integral do aluno.

Ao entendermos a importância da música como conteúdo necessário à formação do pedagogo acreditamos que os cursos de formação inicial precisam abordar a música em seus currículos além das outras linguagens artísticas valorizando e ampliando, dessa forma, o fazer em sala de aula desse profissional tão importante para a construção de uma sociedade mais justa e acessível para todos.

\section{REFERÊNCIAS}

BRASIL. Ministério da educação. Conselho Nacional de Educação. Conselho Pleno Resolução no 1, de 18 de fevereiro de 2002. Institui Diretrizes Curriculares Nacionais para a Formação de Professores da Educação Básica, em nível superior, curso de licenciatura, de graduação plena. Brasília, 2002.

. Lei n. 9.394, de 20 de dezembro de 1996. Estabelece as diretrizes e bases da educação nacional. Diário Oficial da União, Brasilia, DF, 20 dez. 1996. Disponível em: < http://www.planalto.gov.br/ccivil_03/leis/L9394.htm >. Acesso em: 13 ago. 2017.

, Lei n. 11.769 de 18 de Agosto de 2008. Altera a Lei n. 9394/96, para dispor sobre a obrigatoriedade do Ensino de Música na Educação Básica. Brasília: Presidência da República, 2008. Dísponivel em: < http://www.planalto.gov.br/ccivil 03/ ato2007-2010/2008/lei/l11769.htm > Acesso em: 13 de ago. 2017.

, Lei de Diretrizes e Bases da Educação Nacional. Lei 5692 de 11 de Agosto de 1971. Brasí-

lia: Presidência da República, 1971. Acessado em: <
https://presrepublica.jusbrasil.com.br/legislacao/128525/lei-de-diretrizes-e-base-de-1971-lei5692-71 >. Acesso em: 13 de ago. 2017.

. Ministério da Educação e do Desporto. Secretaria de Educação Fundamental. Parâmetros Curriculares Nacionais. Brasília: MEC, a.v. 6: Arte, 1997.

. Ministério da Educação e do Desporto. Secretaria de Educação Fundamental. Parâmetros Curriculares Nacionais. (5a a 8a séries) Arte, Brasília: MEC, 1998.

- Ministério da Educação. Secretaria de Educação Média e Tecnológica. Parâmetros curriculares nacionais: ensino médio. Brasília, 1999. Edição em volume único. Incluindo Lei 9394/96 e Diretrizes Curriculares Nacionais para o Ensino Médio. 
BRÉSCIA, Vera Lúcia Pessagno. Educação Musical: bases psicológicas e ação preventiva. São Paulo: Átomo, 2003.

FARIA, L. C. F. Da sala de estar à sala de aula: Educação Musical por meio de jogos eletrônicos. São Paulo: Paco Editorial, 2016.

FIGUEIREDO, S. L. F. A preparação musical de professores generalistas no Brasil. Revista da ABEM, v. 11, p. 55-61, 2004.

FREIRE, P. Pedagogia da Autonomia: Saberes necessários a prática educativa. São Paulo: Paz e Terra, 1996.

GAINZA, Violeta Hemsy de. Estudos de Psicopedagogia Musical. 3. ed. São Paulo: Summus, 1988.

GARCIA, C. M. Formação de Professores: Para uma mudança Educativa. Portugal: Porto, 1999. 